\title{
ADUBAÇÃO N-K NO ABACAXIZEIRO 'BRS IMPERIAL' - I - EFEITO NO DESENVOLVIMENTO E NA FLORAÇÃO DA PLANTA ${ }^{1}$
}

\author{
ARLENE MARIA GOMES OLIVEIRA ${ }^{2}$, WILLIAM NATALE ${ }^{3}$ \\ RAUL CASTRO CARRIELLO ROSA ${ }^{2}$, DAVI THEODORO JUNGHANS ${ }^{2}$
}

RESUMO - O abacaxizeiro 'BRS Imperial' é cultivar resistente à fusariose, com folhas sem espinhos, e que carece de informações técnicas específicas para o seu manejo. Este trabalho teve como objetivo avaliar o efeito de doses de $\mathrm{Ne} \mathrm{K}_{2} \mathrm{O}$ no desenvolvimento vegetativo, na floração e nos atributos de desenvolvimento da folha 'D' do 'BRS Imperial', buscando estabelecer parâmetros da planta para a indução artificial do florescimento. Em delineamento em blocos ao acaso e cinco repetições, testaram-se quatro doses de N $(0 ; 160 ; 320 ; 550$ $\left.\mathrm{kg} \mathrm{ha}^{-1}\right)$ e quatro doses de $\mathrm{K}_{2} \mathrm{O}\left(0 ; 240 ; 480\right.$ e $\left.600 \mathrm{~kg} \mathrm{ha}^{-1}\right)$, em esquema fatorial completo 4 x 4 . A adubação potássica influenciou de forma positiva na massa fresca e no comprimento da planta, bem como no número de mudas por planta após a colheita dos frutos, enquanto a aplicação de $\mathrm{N}$ influenciou na emissão de folhas e na massa fresca de mudas. A adubação nitrogenada diminuiu o percentual de florescimento induzido artificialmente, enquanto a potássica aumentou esse parâmetro. A massa máxima estimada da folha ' $D$ ' foi de $56 \mathrm{~g}$ na dose de $364 \mathrm{~kg} \mathrm{ha}^{-1}$ de $\mathrm{N}$ e na maior dose de $\mathrm{K}_{2} \mathrm{O}\left(600 \mathrm{~kg} \mathrm{ha}^{-1}\right)$. A massa da folha ' $\mathrm{D}$ ' apresentou a melhor correlação com a massa do fruto, sendo estimada a massa mínima de $44 \mathrm{~g}$ para obtenção de frutos de 900 g, massa mínima exigida pelo mercado para comercialização.

Termos para indexação: Ananas comosus var. comosus, abacaxi, folha 'D', nutrição de planta.

\section{NK FERTILIZATION IN 'BRS IMPERIAL' PINEAPPLE I - EFFECT ON DEVELOPMENT AND PLANT FLOWERING}

\begin{abstract}
The 'BRS Imperial' pineapple is a resistant cultivar to Fusarium, with leaves without thorns, but it requires a specific technical information for its management. This study aimed to evaluate the effect of different levels of $\mathrm{N}$ and $\mathrm{K}_{2} \mathrm{O}$ on vegetative growth, flowering and in the attributes of ' $\mathrm{D}$ ' leaf development of 'BRS Imperial' pineapple, in order to determinate the plant parameters to induce artificial flowering. In a complete randomized block design with five replications, we tested four $\mathrm{N}\left(0,160,320,550 \mathrm{~kg} \mathrm{ha}^{-1}\right)$ and four $\mathrm{K}_{2} \mathrm{O}\left(0,240,480\right.$ and $\left.600 \mathrm{~kg} \mathrm{ha}^{-1}\right)$ levels, in a complete factorial $4 \mathrm{x} 4$. Potassium fertilization positively influenced in fresh mass and plant length, as well as the number of slip per plant; while the nitrogen fertilization influenced the leaf emergence and fresh mass of slip. Nitrogen fertilization decreased the artificially induced flowering, while potassium increased the flowering rate. The maximum mass of the ' $\mathrm{D}$ ' leaf was estimated at $56 \mathrm{~g}$, in the dose of $364 \mathrm{~kg} \mathrm{~N}^{-1}$ and higher dose of potassium fertilizer $\left(600 \mathrm{~kg} \mathrm{ha}^{-1} \mathrm{~K}_{2} \mathrm{O}\right)$. The mass of ' $\mathrm{D}$ ' leaf showed the best correlation with fruit mass and estimated the minimum mass of $44 \mathrm{~g}$ to obtain 900 $\mathrm{g}$ of fruit, the minimum mass required by the market for sale.

Index terms: Ananas comosus var. comosus, pineapple, vegetative development, 'D' leaf, plant nutrition.
\end{abstract}

${ }^{1}$ (Trabalho 023-*14). Recebido em: 16-01-2014. Aceito para publicação em: 23-04-2015. Dados da tese do primeiro autor na UNESP Jaboticabal-SP

${ }^{2}$ DSc; Pesquisador; Embrapa Mandioca e Fruticultura; Rua Embrapa, s/n, CEP 44380-000, Cruz das Almas-BA. Emails: arlene. oliveira@embrapa.br; raul.rosa@embrapa.br; davi.junghans@embrapa.br

${ }^{3}$ DSc; Professor Convidado; Université Laval, Québec, Canadá. E-mail: william.natale@fsaa.ulaval.ca 


\section{INTRODUÇÃO}

O abacaxizeiro 'BRS Imperial' é cultivar resistente à fusariose, principal doença desta cultura no Brasil, com folhas sem espinhos o qual tem grande potencial comercial devido à excelente aceitação de seus frutos.

Diversos são os parâmetros utilizados para avaliar o desenvolvimento vegetativo do abacaxizeiro, podendo-se citar o número e a massa de folhas; a massa, o comprimento e a largura da folha ' $D$ '; a altura e a massa das plantas; bem como o tipo, o número e a massa das mudas. O comprimento máximo da folha é atingido alguns meses após o início de sua formação. O tempo desde o início de sua formação até ao seu alongamento completo depende da temperatura, levando quatro meses nas condições equatoriais da Costa do Marfim e mais tempo em ambientes mais frios (MALEZIEUX et al., 2003; GIACOMELLI, 1982). A folha ' $D$ ' do abacaxizeiro é a folha mais comprida na planta e é comumente usada para avaliar o índice de crescimento e o estado nutricional da planta.

Van de Poel et al. (2009), trabalhando com o híbrido MD-2, com mudas grandes, de massa entre 450 e $500 \mathrm{~g}$, provenientes da soca de cultivo de abacaxizeiro, observaram que as plantas a partir dos três meses de idade eram totalmente sensíveis à indução do florescimento com tratamento por etileno, ou seja, neste estádio, já atingiram a maturidade. O comprimento e a massa fresca da folha ' $D$ ' mostraram relação estreita com a maturidade da planta, estabelecida em função do florescimento. Dessa forma, esses parâmetros de campo podem ser utilizados de modo eficiente para indicar a maturidade e o momento adequado para a indução do florescimento da planta (VAN DE POEL et al., 2009).

A indução ao florescimento, de forma natural ou artificial, interrompe a produção de folhas e inicia o processo de diferenciação floral, com a floração tornando-se visível em torno de seis semanas mais tarde (GIACOMELLI, 1982). A adubação parece exercer efeito sobre o processo de florescimento. Hepton (2003) relata que o efeito das baixas temperaturas e de fotoperíodos curtos durante o inverno sobre o florescimento natural pode ser reduzido em plantas de abacaxizeiro, mantendo-se os níveis de $\mathrm{N}$ altos na planta; mas o $\mathrm{N}$, por si só, não pode eliminar a diferenciação se a temperatura do ar ficar abaixo de $15^{\circ} \mathrm{C}$. Kist et al. (2011) observaram no cerrado de Mato Grosso que a indução floral realizada nos meses de maio e julho, período de baixas temperatura e precipitação, alongou o ciclo da planta, diminuindo a massa dos frutos e o comprimento da folha ' $D$ '. A indução realizada em setembro e novembro determinou a colheita em épocas favoráveis de comercialização, independentemente do mês de plantio, sem interferência na massa dos frutos.

Na Bahia, a 'BRS Imperial' apresentou comprimento da folha ' $\mathrm{D}$ ' de $68 \mathrm{~cm}$, com frutos (com coroa) de 1,8 kg de massa (CABRAL;MATOS, 2009). Porém, o desenvolvimento da planta está diretamente relacionado à adubação aplicada (GUARÇONI M;VENTURA, 2011; SILVA et al., 2012), que influencia, também, no comprimento e na massa da folha 'D'. Como existe correlação positiva entre os parâmetros de desenvolvimento da planta e a massa dos frutos (GUARÇONI M; VENTURA, 2011; SILVA et al., 2012), pode-se manejar a cultura de forma a se obter o tamanho do fruto que atenda às exigências do mercado a que se destina à produção. Dessa forma, o conhecimento dos aspectos que interferem no crescimento vegetativo do abacaxizeiro no campo é determinante para o alcance dos objetivos almejados e devem ser investigados.

Este trabalho teve como objetivo avaliar o efeito de doses de $\mathrm{N}_{\text {e }} \mathrm{K}_{2} \mathrm{O}$ no desenvolvimento vegetativo, na floração e nos atributos de desenvolvimento da folha ' $\mathrm{D}$ ' do abacaxizeiro 'BRS Imperial', buscando-se estabelecer parâmetros da planta para a indução artificial ao florescimento.

\section{MATERIAL E MÉTODOS}

O experimento foi instalado na Fazenda Bom Sossego, localizada a $16^{\circ} 22^{\prime}$ '26" sul e $39^{\circ} 04^{\prime}$ '52" W, no município de Porto Seguro, Bahia, em um Argissolo Amarelo distrófico típico, A moderado, textura arenosa/média/argilosa. Para análise química da camada de solo de $0-20 \mathrm{~cm}$ de profundidade, foram coletadas 20 amostras simples para formar uma amostra composta, que apresentou as seguintes características químicas: $\mathrm{pH}$ em água $(1: 2,5)=6,1$; $\mathrm{P}=5 \mathrm{mg} \mathrm{dm}{ }^{-3} ; \mathrm{K}^{+}=0,17 ; \mathrm{Ca}^{2+}=2,40 ; \mathrm{Mg}^{2+}=0,80 ;$ $\mathrm{Al}^{3+}=0 ; \mathrm{Na}^{+}=0,08 ; \mathrm{H}+\mathrm{Al}=3,19$ e $\mathrm{CTC}=6,64$ (todos em $\mathrm{cmol}_{\mathrm{c}} \mathrm{dm}^{-3}$ ); Matéria Orgânica $=17,07$ $\mathrm{g} \mathrm{kg}^{-1} ; \mathrm{B}=0,24 ; \mathrm{Cu}=0,1 ; \mathrm{Fe}=69 ; \mathrm{Mn}=0,4 ; \mathrm{Zn}$ $=0,2$ e $\mathrm{S}_{-} \mathrm{SO}_{4}=6$ (todos em $\mathrm{mg} \mathrm{dm}^{-3}$ ). A análise granulométrica simples apresentou, em $\mathrm{g} \mathrm{kg}^{-1}$, argila $=256$; silte $=35$; areia fina $=152$ e areia grossa $=$ 557, situando-se na classe textural média.

O plantio, realizado em abril de 2011, foi instalado no espaçamento $0,90 \times 0,40 \times 0,40 \mathrm{~m}$, testando-se quatro doses de $\mathrm{N}\left(0 ; 160 ; 320\right.$ e $\left.550 \mathrm{~kg} \mathrm{ha}^{-1}\right)$ e quatro doses de $\mathrm{K}_{2} \mathrm{O}\left(0 ; 240 ; 480\right.$ e $\left.600 \mathrm{~kg} \mathrm{ha}^{-1}\right)$, em delineamento experimental de blocos ao acaso, com 
cinco repetições, em fatorial completo $4 \times 4$, com parcelas de bordadura dupla, totalizando 72 plantas, onde 40 plantas eram úteis. Foram utilizadas mudas obtidas pelo método de seccionamento do talo, com massas que variaram de 50 a $90 \mathrm{~g}$. Os tratos culturais, adubação e parcelamento de adubos, foram realizados segundo as recomendações para o cultivo do abacaxizeiro 'Pérola', na região Extremo Sul da Bahia (OLIVEIRA et al., 2009). Foram aplicadas na cova de plantio $14 \mathrm{~g}$ de superfosfato simples e 4,9 $\mathrm{g}$ de FTE BR-12. As doses de $\mathrm{N}$ e $\mathrm{K}_{2} \mathrm{O}$ foram parceladas em quatro aplicações, aos 60; 120; 180 e 270 dias após o plantio (DAP), correspondentes às seguintes percentagens do total aplicado no ciclo da cultura: 19 e $25 \%$ na primeira e na segunda parcelas, e $28 \%$ na terceira e na quarta parcelas, tendo como fontes de $\mathrm{N}$ a ureia, e de $\mathrm{K}$, o cloreto de potássio. As doses de adubos foram diluídas em água e aplicadas no solo junto à base da planta.

Os dados climatológicos informados pelo INMET e os obtidos na sede da Fazenda Bom Sossego estão apresentados na Figura 1. $\mathrm{O}$ experimento foi realizado em condições de sequeiro, com irrigação suplementar nos meses de fevereiro, março e abril de 2012, utilizando-se de microaspersores suspensos acima das plantas, com vazão de $35 \mathrm{~L} \mathrm{~h}^{-1}$. Foram aplicados 69; 46 e $79 \mathrm{~mm}$ de água nos meses de fevereiro, março e abril de 2012 que, somados à precipitação mensal ocorrida na Fazenda Bom Sossego, totalizaram 93; 169 e $87 \mathrm{~mm}$, respectivamente. O conteúdo total de água identificado como PFAZ na Figura 1 trata-se da quantidade de chuva medida pelo pluviômetro da Fazenda Bom Sossego, em todos os meses do ano, com exceção de fevereiro, março e abril de 2012, em que foi computada também a água proveniente de irrigação realizada devido à ausência prolongada de chuvas na região. Os dados do INMET de precipitação, em 2012, nos meses de fevereiro, março e abril, e as temperaturas do ar, nos meses de fevereiro, março, abril, julho, agosto e setembro, não foram registrados pelo INMET.

As avaliações de desenvolvimento das plantas foram realizadas com auxílio de uma balança digital (erro $=0,05 \mathrm{~g}$ ) e trena milimétrica. A partir dos quatro meses após o plantio, foram marcadas as folhas mais novas em 40; 20 e 10 plantas úteis por parcela, para a avaliação do número de folhas emitidas aos $6 ; 8$ e 10 meses após o plantio, respectivamente. O número de folhas total foi obtido pelo somatório de todas as folhas emitidas dos 4 aos 10 meses após o plantio. Aos 12 meses e 10 dias, foram selecionadas quatro plantas de cada tratamento para a coleta da folha ' $\mathrm{D}$ ' e a avaliação de sua massa (g), de seu comprimento (cm) e de sua largura $(\mathrm{cm})$.

A indução floral foi realizada aos 13 meses após o plantio (maio de 2012), com Ethrel (24\%). Em caixa d'água de $250 \mathrm{~L}$, contendo cerca de 200 $\mathrm{L}$ de água, adicionaram-se um 1L de Ethrel, $25 \mathrm{~g}$ de hidróxido de cálcio, $6 \mathrm{~kg}$ de gelo, completando-se com água. Aplicaram-se $40 \mathrm{~mL}$ dessa solução na roseta foliar das plantas e, após dois dias, a operação foi repetida. A repetição foi realizada pelo fato de observações empíricas indicarem maior resistência desta cultivar à indução floral e por ter chovido no dia da indução. Aos 50 e 60 dias após a indução, foi contado o número de plantas da parcela útil, que apresentavam a inflorescência visível a olho nu.

A colheita teve início em 02-10-2012 (17 meses após o plantio), estendendo-se por três meses. Foram determinados as massas dos frutos com coroa (dados não apresentados) e o número e a massa de mudas do tipo filhote. Após a colheita de todos os frutos, selecionaram-se duas das quatro plantas utilizadas para a amostragem da folha ' $\mathrm{D}$ '. As raízes foram eliminadas e determinaram-se a massa fresca e o comprimento da planta (da base da planta até à folha mais comprida), bem como o número de rebentões presentes na base do caule.

Os dados foram submetidos ao teste $\mathrm{F}$ da análise de variância, enquanto as médias dos tratamentos foram ajustados pelos modelos de regressão polinomial. Os modelos foram escolhidos em função de sua significância, pelo teste $\mathrm{F}$ da análise de variância e pelo valor do coeficiente de determinação $\left(\mathrm{R}^{2}\right)$. Para estabelecer as regressões lineares entre as variáveis de desenvolvimento da folha ' $\mathrm{D}$ ' e do fruto, foram pareados 278 dados de frutos e suas respectivas folhas ' $\mathrm{D}$ '. Foram também calculados os coeficientes de correlação linear de Pearson; e suas significâncias, testadas pelo teste t, a $5 \%$ de probabilidade, visando a evidenciar o nível de associação entre variáveis de desenvolvimento e de produção do abacaxizeiro. As análises foram realizadas com o auxílio do programa estatístico SAEG (UFV, 1997).

\section{RESULTADOS E DISCUSSÃO}

Não houve interação significativa entre $\mathrm{N}$ e $\mathrm{K}_{2} \mathrm{O}$ nas variáveis de desenvolvimento das plantas e de floração avaliadas pela análise de variância $(p<0,05)$. Na Tabela 1, são apresentadas as significâncias do teste $\mathrm{F}$, as regressões ajustadas, os valores de $\mathrm{R}^{2}$, as doses máximas e mínimas de $\mathrm{N}$ e $\mathrm{K}_{2} \mathrm{O}$ estimadas pelos modelos quadráticos e lineares aplicados e respectivas estimativas das variáveis. 


\section{Emissão de Folhas}

A adubação nitrogenada influenciou positivamente a emissão de folhas em todas as avaliações. Os modelos de regressão ajustados aos dados apresentaram comportamento quadrático em relação às doses de $\mathrm{N}$, nas avaliações, aos 6 e aos 10 meses após o plantio, e linear aos 8 meses de idade (Tabela 1). A emissão de folhas entre os 6 e 8 meses foi maior que entre os 4 e 6 meses, decrescendo posteriormente entre os 8 e 10 meses após o plantio. No período compreendido entre os 4 e os 10 meses de idade da planta, foram emitidas 27,0 folhas na dose máxima estimada de $405 \mathrm{~kg} \mathrm{ha}^{-1}$ de $\mathrm{N}$.

A adubação potássica influenciou apenas na fase de maior maturidade da planta, ou seja, entre os 8 e 10 meses após o plantio, observando-se comportamento linear crescente (Tabela 1).

Resultados diferentes foram observados por Pinheiro Neto (2009), que ao testar doses de N e K não observou efeito do adubo nitrogenado no número de folhas da cultivar MD-2 sob irrigação, enquanto a menor dose de $\mathrm{K}$ testada apresentou o maior número de folhas. Diferentes comportamentos também foram observados por Razzaque e Hanafi (2001) que, ao avaliarem o número de folhas da cv. Gandul (do grupo Singapore Spanish), com 10 meses de idade, cultivada em diferentes níveis de potássio, não observaram efeito significativo do K sobre o número de folhas. Da mesma forma, Ramos (2006) não observou efeito da adubação potássica no número de folhas do 'BRS Imperial', porém a deficiência de N reduziu significativamente o número de folhas. Neste experimento, as nove folhas emitidas a cada dois meses estão de acordo com os relatos de Giacomelli (1982), para condições climáticas favoráveis, como as observadas no período deste estudo (Figura 1).

\section{Folha 'D' e Floração}

As diferentes doses de $\mathrm{Ne} \mathrm{K}_{2} \mathrm{O}$ influenciaram significativamente na massa da folha ' $\mathrm{D}$ '. As determinações de largura da folha mostraram diferenças significativas apenas para as doses de $\mathrm{K}_{2} \mathrm{O}$, enquanto o comprimento da folha não mostrou diferença estatística (Tabela 1). Ramos et al. (2013) não observaram no abacaxizeiro 'BRS Imperial', na ausência de $\mathrm{N}$ e $\mathrm{K}$, diferenças significativas na largura, enquanto apenas a ausência de $\mathrm{N}$ influenciou no comprimento da folha ' $\mathrm{D}$ '. Da mesma forma, Silva et al. (2012) observaram influência de doses crescentes de N sobre o comprimento da folha 'D' do abacaxizeiro 'Vitória'.

O comprimento médio da folha ' $\mathrm{D}$ ' foi de $75,15 \mathrm{~cm}$, superior aos $68 \mathrm{~cm}$ observados por Cabral e Matos (2009) durante o processo de seleção desta cultivar. Da mesma forma, para o 'BRS Imperial', Ramos et al. (2013) e Sampaio et al. (2011) obtiveram valor inferior do comprimento da folha 'D' $(63 \mathrm{~cm}) \mathrm{em}$ plantas com 8 meses de plantio em casa de vegetação e aos 13/14 meses em campo, respectivamente. Guarçoni M. e Ventura (2011) observaram resultados diferentes para a cultivar de abacaxi Gold (MD-2), verificando resposta quadrática para as doses de $\mathrm{N}$ e $\mathrm{K}_{2} \mathrm{O}$, em relação ao comprimento da folha ' $\mathrm{D}$ ', que foi estimada em $76,6 \mathrm{~cm}$.

A massa da folha ' $\mathrm{D}$ ' apresentou correlações lineares de Pearson (todas significativas a 1\% de probabilidade, pelo teste $\mathrm{t}$ ), de 0,80 com o comprimento, enquanto as correlações entre a massa e a largura, assim como entre o comprimento e a largura foram mais baixas, da ordem de 0,66 e 0,44, respectivamente. A análise de regressão dos dados da massa da folha ' $D$ ' em função das doses de $\mathrm{N}$ resultou em modelo quadrático de resposta (Tabela 1), enquanto houve significância ajustada a um modelo linear, tanto para a massa como para a largura das folhas 'D' nas diferentes doses de $\mathrm{K}_{2} \mathrm{O}$. Ramos (2006) obteve, também, menor massa de matéria fresca da folha 'D' de 'BRS Imperial' sob deficiência de N e K. Sampaio et al. (2011) observaram a massa da folha 'D' do 'BRS Imperial' de $34 \mathrm{~g}$, inferior ao observado no presente experimento. Esse valor para folha ' $\mathrm{D}$ ' correspondeu a frutos com coroa de $670 \mathrm{~g}$, inferior ao máximo observado neste estudo, que foi de $1.086 \mathrm{~g}$ (dado não apresentado). Por outro lado, Guarçoni, M. e Ventura (2011), trabalhando com a massa seca da folha ' $\mathrm{D}$ ', obtiveram resposta quadrática, não só para $\mathrm{N}$, mas também para $\mathrm{K}$. Porém, a dose máxima de $\mathrm{N}$ estimada por esses autores $\left(638 \mathrm{~kg} \mathrm{ha}^{-1}\right)$ foi superior à obtida para o abacaxizeiro 'BRS Imperial', enquanto a dose máxima de $\mathrm{K}_{2} \mathrm{O}\left(571,9 \mathrm{~kg} \mathrm{ha}^{-1}\right)$ foi inferior à maior dose de $\mathrm{K}_{2} \mathrm{O}$ testada no presente trabalho. $\mathrm{O}$ aumento da massa da folha ' $\mathrm{D}$ ' devido ao incremento de $\mathrm{K}$ está relacionado ao papel que esse nutriente desempenha na planta, nos processos bioquímicos e fisiológicos, principalmente na fotossíntese e na translocação de carboidratos dentro da planta (MALAVOLTA, 2006).

$\mathrm{O}$ aumento das doses de $\mathrm{N}$ promoveu a diminuição da porcentagem de florescimento de forma linear, tanto aos 50 como aos 60 dias após a indução artificial (Tabela 1). Isso é corroborado por Hepton (2003) que cita que o fornecimento de $\mathrm{N}$ e de água para manter o crescimento vegetativo ativo da planta pode diminuir o florescimento. Esse efeito do $\mathrm{N}$ pode ter contribuído com o alongamento do período de colheita por três meses. Inversamente, o incremento das doses de $\mathrm{K}_{2} \mathrm{O}$ promoveu aumento linear da porcentagem de florescimento em ambas 
as épocas avaliadas. Em relação ao florescimento natural, Teixeira et al. (2011) observaram que o índice de florescimento diminuiu conforme aumentaram as doses de $\mathrm{K}_{2} \mathrm{O}$, aplicadas na forma de $\mathrm{KCl}$, não tendo sido observado atraso significativo no florescimento devido ao uso de $\mathrm{K}_{2} \mathrm{SO}_{4}$. Os autores consideram que o efeito prejudicial do $\mathrm{Cl}$ na planta causou o atraso do florescimento, que permitiu maior tempo para o crescimento das plantas, mas que não se refletiu em produção. Pelos resultados observados neste experimento, pode-se inferir que o $\mathrm{K}$, mesmo na forma de cloreto de potássio, exerce efeito contrário na floração ao observado por Teixeira et al. (2011), quando o florescimento é induzido artificialmente.

\section{Desenvolvimento das plantas e mudas}

A massa e o comprimento da planta após a colheita dos frutos foram afetados significativamente apenas pelas doses de $\mathrm{K}_{2} \mathrm{O}$, de forma linear e crescente (Tabela 1). Teixeira et al. (2011), trabalhando com 'Smooth Cayenne', observaram aumento linear da massa da matéria seca da planta e da área foliar em função das doses de $\mathrm{K}_{2} \mathrm{O}$. Por outro lado, Razzaquea e Hanafi (2001), em estudo com a cv. Gandul, não observaram efeito do K sobre a altura da planta que se situou na faixa de 103,6 a $115,0 \mathrm{~cm}$ após 10 meses de cultivo. Para o 'BRS Imperial', Cabral e Matos (2009) observaram o comprimento da planta de $49,1 \mathrm{~cm}$, determinado do solo até à base do fruto. Os resultados desses autores demonstram que os atributos de desenvolvimento das plantas variam entre cultivares, práticas culturais e condições edafoclimáticas.

A análise de variância dos dados de número e massa de mudas mostrou significância para as doses de $\mathrm{N}$ apenas para a massa de mudas, diferentemente do observado por Faria (2008), que relatou influência da adubação nitrogenada no número de mudas do tipo filhote. Pela análise de regressão, as doses de $\mathrm{N}$ mostraram efeito quadrático na massa das mudas (Tabela 1), enquanto a análise de variância dos dados mostrou que $\mathrm{K}_{2} \mathrm{O}$ influenciou apenas no número de mudas. A correlação obtida de 0,70 , significativa a $1 \%$ de probabilidade, entre o número de mudas e a massa do fruto (Tabela 2), indica que existe associação entre essas variáveis, o que pode explicar a diferença observada no número de mudas por Cabral e Matos (2009) para o 'BRS Imperial', que obtiveram 9 mudas para frutos de $1.692 \mathrm{~g}$, superior ao encontrado neste experimento (1.086 g). As adubações nitrogenada e potássica não influenciaram no número de rebentões emitidos, com média de 0,5 rebentão por planta, diferente de Cabral e Matos (2009), que observaram, em média, um rebentão por planta.

\section{Correlações}

Todos os parâmetros de desenvolvimento das plantas e dos materiais reprodutivos correlacionaramse positiva e significativamente com os atributos dos frutos, com exceção do número de rebentões (Tabela 2). Plantas mais desenvolvidas e, consequentemente, com maior número de folhas produziram frutos maiores e mais pesados. Porém, essas características são variáveis entre as cultivares e dependem das práticas culturais empregadas, conforme citado anteriormente.

As massas dos frutos, com e sem coroa, apresentaram significância nos testes de correlação e de regressão linear com a massa e o comprimento da folha ' $D$ ' (Tabela 2). Os melhores coeficientes de determinação e de correlação foram observados entre a massa a folha ' $D$ ' e a massa do fruto. Utilizando-se da massa máxima observada da folha ' $\mathrm{D}$ ' (56 g), a massa do fruto estimado pela regressão (Figura 2) seria de $1.096 \mathrm{~g}$, bem próximo da massa máxima de $1.086 \mathrm{~g}$ obtida neste experimento, na dose máxima física de $\mathrm{N}$ (dado não apresentado). Considerando que a massa mínima do fruto para comercialização deva ser maior ou igual a $900 \mathrm{~g}$ (HORTIESCOLHA, 2015), a massa mínima da folha ' $D$ ' deverá ser de $44 \mathrm{~g}$ para a realização da indução floral. Para a faixa de frutos dos tipos médio e graúdo, considerando os limites inferiores de $1.200 \mathrm{e} 1.800 \mathrm{~g}$, a massa da folha 'D'deverá ser de 62 e $99 \mathrm{~g}$, respectivamente. Embora possam ser encontrados frutos com massas acima de $1.800 \mathrm{~g}$, até o momento, nenhum trabalho relatou frutos com massa média nesse patamar, sendo os frutos dessa cultivar considerados de miúdo a médio. Santos Filho et al. (2011) determinaram que a melhor correlação $(0,75)$ foi obtida entre a massa fresca da folha ' $D$ ' e a massa do fruto sem coroa, embora recomendem o uso da massa do fruto com coroa, para efeito de comercialização. Pelas regressões obtidas pelos autores, para alcançar frutos com massa maior ou igual a $900 \mathrm{~g}$, a folha ' $\mathrm{D}$ ' deve ter $54 \mathrm{~g}$ de massa, superior ao estimado pela regressão no presente trabalho. Porém, os autores não informaram o coeficiente de correlação, não sendo possível inferir pela regressão o percentual da massa do fruto, que pode ser explicada pela variabilidade da massa da folha ' $\mathrm{D}$ '. No presente trabalho, o coeficiente de determinação da regressão linear entre a massa da folha ' $D$ ' e a massa do fruto indica que $32 \%$ da massa do fruto é explicada pela variabilidade da massa da folha 'D' (Figura 2).

As análises de correlação e de regressão entre a massa do fruto e o comprimento da folha ' $D$ ', embora significativas, apresentaram coeficiente 
de correlação (Tabela 2) e de determinação (Figura 2) menor que entre a massa do fruto e massa da folha 'D'. Santos Filho et al. (2011) relataram comprimento superior $(77 \mathrm{~cm})$ para atingir a massa do fruto de $900 \mathrm{~g}$. Portanto, o comprimento da folha ' $D$ ' do abacaxizeiro 'BRS Imperial' parece não ser o parâmetro mais indicado para definir o momento da indução artificial para essa cultivar.
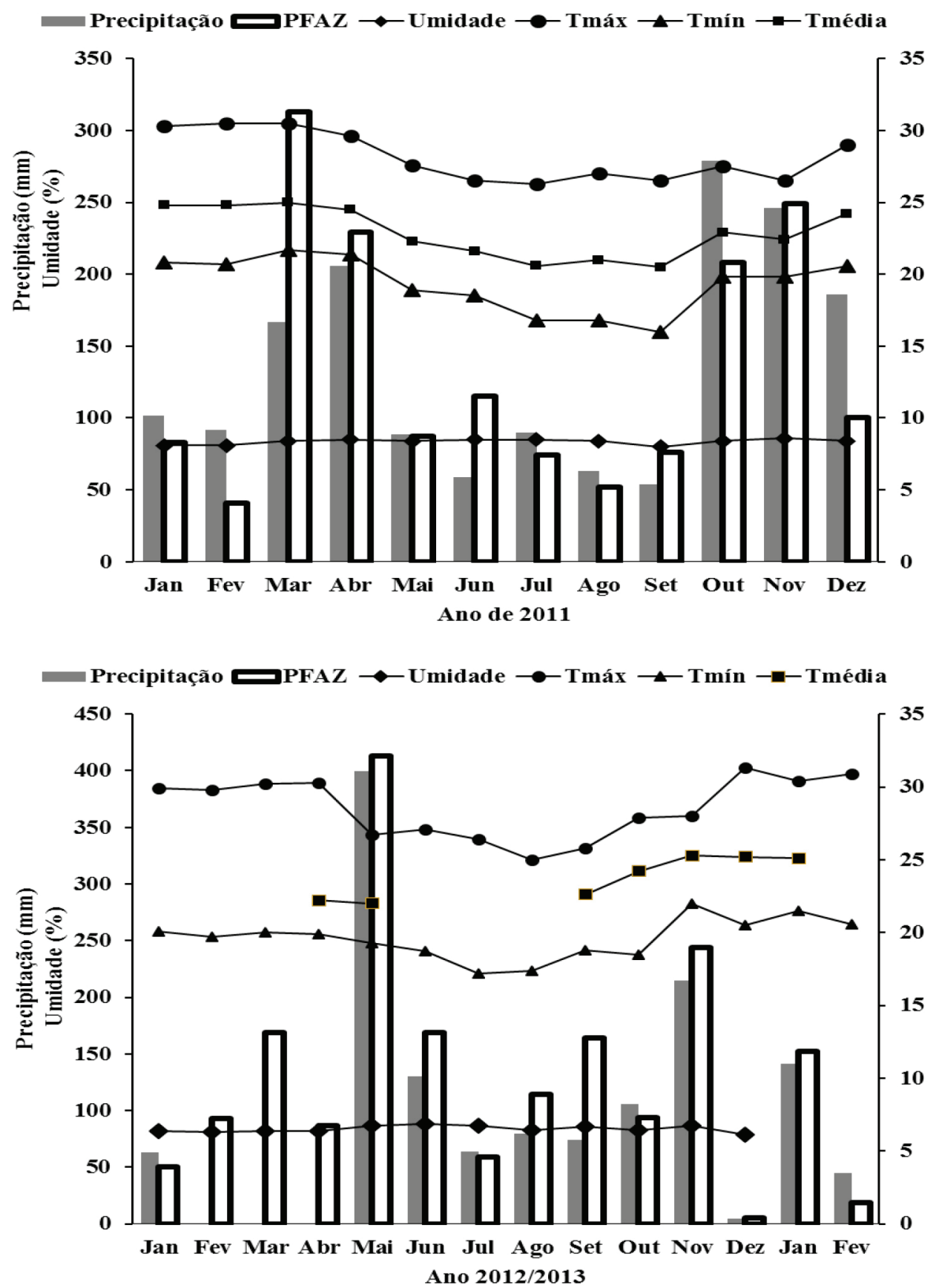

FIGURA 1- Dados da estação meteorológica automática de Porto Seguro-BA, Lat: 16 23' S Long: 39 10'W Alt: 85 metros, Instituto Nacional de Meteorologia - INMET, Ministério da Agricultura, Pecuária e Abastecimento - MAPA, dos anos 2011, 2012 e parte de 2013, de precipitação pluvial, temperatura do ar média (Tmédia), máxima (Tmáx) e mínima (Tmín) e umidade relativa do ar. Dados pluviométricos + irrigação (PFAZ), obtidos na sede da Fazenda Bom Sossego. 
TABELA 1- Significância do Teste F, regressões ajustadas, $\mathrm{R}^{2}$, dose máxima ou mínima física e estimativa das variáveis de desenvolvimento e de floração de plantas de abacaxizeiro 'BRS Imperial', em função de doses de nitrogênio e potássio. Porto Seguro-BA. 2013.

\begin{tabular}{|c|c|c|c|c|}
\hline Variáveis/ ${ }^{1}$ & Análise de Regressão & $\mathrm{R}^{2}$ & $\operatorname{Dose}^{/ 2}\left(\mathrm{~kg} \mathrm{ha}^{-1}\right)$ & Estimativa $^{/ 3}$ \\
\hline $\mathrm{NF} 1 * *$ & 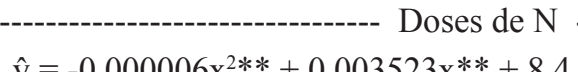 & 090 & 204 & 89 \\
\hline NF2* & $\hat{\mathrm{y}}=0,001329 \mathrm{x} *+8,6$ & 0,86 & 550 & 9,3 \\
\hline $\mathrm{NF} 3 * *$ & $\hat{y}=-0,000006 x^{2 * *}+0,004709 x * *+8,1$ & 0,99 & 392 & 9,0 \\
\hline NFT** & $\hat{y}=-0,00001 x^{2 * *}+0,0105 x+24,9$ & 0,96 & 405 & 27 \\
\hline $\operatorname{MFD}(\mathrm{g}) *$ & $\hat{y}=0,000035 x^{2 *}+0,025456 x+51,5$ & 0,92 & 364 & 56 \\
\hline FLOR50 $(\%)^{* *}$ & $\hat{y}=-0,0448 x^{* *}+96$ & 0,98 & 550 & 71 \\
\hline FLOR60 $(\%)^{* *}$ & $\hat{y}=-0,0336 x * *+99$ & 0,92 & 550 & 81 \\
\hline NF3** & $\hat{y}=0,001222 x * *+8,3$ & 0,98 & 600 & 9,0 \\
\hline $\operatorname{MFD}(\mathrm{g})^{* *}$ & $\hat{y}=0,007652 x^{* *}+51,7$ & 0,96 & 600 & 56 \\
\hline $\mathrm{LFD}^{* *}(\mathrm{~mm})$ & $\hat{y}=0,007534 x^{* *}+48,6$ & 0,96 & 600 & 53 \\
\hline FLOR50 $(\%)^{* *}$ & $\hat{\mathrm{y}}=0,0275 \mathrm{x} * *+75$ & 0,93 & 600 & 92 \\
\hline FLOR60 $(\%)^{* *}$ & $\hat{y}=0,0183 x^{* *}+84$ & 0,90 & 600 & 95 \\
\hline $\mathrm{MM}(\mathrm{g})^{*}$ & $\hat{y}=-0,0005 x^{2 *}+0,3479 x * *+289,8$ & 0,96 & 348 & 350 \\
\hline $\mathrm{NM}(\mathrm{g}) *$ & $\hat{y}=-0,000003 x^{2}+0,0025 x * *+7,2$ & 0,98 & 417 & 7,7 \\
\hline $\operatorname{MPL}(\mathrm{g})^{* *}$ & $\hat{y}=0,555844 x^{* *}+1450$ & 0,87 & 600 & 1783 \\
\hline $\mathrm{CPL}(\mathrm{cm})^{* *}$ & $\hat{y}=0,012037 x^{* *}+85,4$ & 0,92 & 600 & 92,6 \\
\hline
\end{tabular}

${ }^{/ 1}$ Número de folhas (NF): NF1 = 4-6 meses, NF2 - 6-8 meses, NF3 = 8-10 meses e NFT = número total emitidas de 4-10 meses; Folha 'D': MFD = Massa, LFD = Largura; Planta: MPL = Massa e COMPL =comprimento; dias após os florescimento: FLOR50 = 50 dias e FLOR60 $=60$ dias

${ }^{12}$ Dose máxima ou mínima estimada pelo modelo aplicado; ${ }^{/ 3}$ Ponto de máximo ou mínimo

**, * significativo a $1 \%$ e $5 \%$ de probabilidade, pelo teste $\mathrm{F}$, respectivamente.

TABELA 2- Correlações de Pearson e significância do teste $t$ das variáveis de desenvolvimento do abacaxizeiro 'BRS Imperial'. Porto Seguro-BA, 2013.

\begin{tabular}{lcccc}
\hline Parâmetros & Peso do Fruto & $\begin{array}{c}\text { Peso do Fruto } \\
\text { Sem Coroa }\end{array}$ & $\begin{array}{c}\text { Diâmetro } \\
\text { do Fruto }\end{array}$ & $\begin{array}{c}\text { Comprimento } \\
\text { do Fruto }\end{array}$ \\
\hline Massa folha 'D' & $0,60^{* *}$ & $0,58^{* *}$ & $0,58^{* *}$ & $0,44^{* *}$ \\
Comprimento folha 'D' & $0,49^{* *}$ & $0,49^{* *}$ & $0,49^{* *}$ & $0,35^{* *}$ \\
№ de Folhas Total & $0,63^{* *}$ & $0,64^{* *}$ & $0,64^{* *}$ & $0,65^{* *}$ \\
№ Mudas & $0,70^{* *}$ & $0,70^{* *}$ & $0,71^{* *}$ & $0,58^{* *}$ \\
Massa Mudas & $0,85^{* *}$ & $0,83^{* *}$ & $0,83^{* *}$ & $0,69^{* *}$ \\
Comprimento da Planta & $0,56^{* *}$ & $0,58^{* *}$ & $0,56^{* *}$ & $0,55^{* *}$ \\
Massa da Planta & $0,59^{* *}$ & $0,61^{* *}$ & $0,55^{* *}$ & $0,58^{* *}$ \\
\hline
\end{tabular}

** Significativo a $1 \%$ de probabilidade; ns não significativo a $5 \%$ de probabilidade, pelo teste $\mathrm{t}$. 

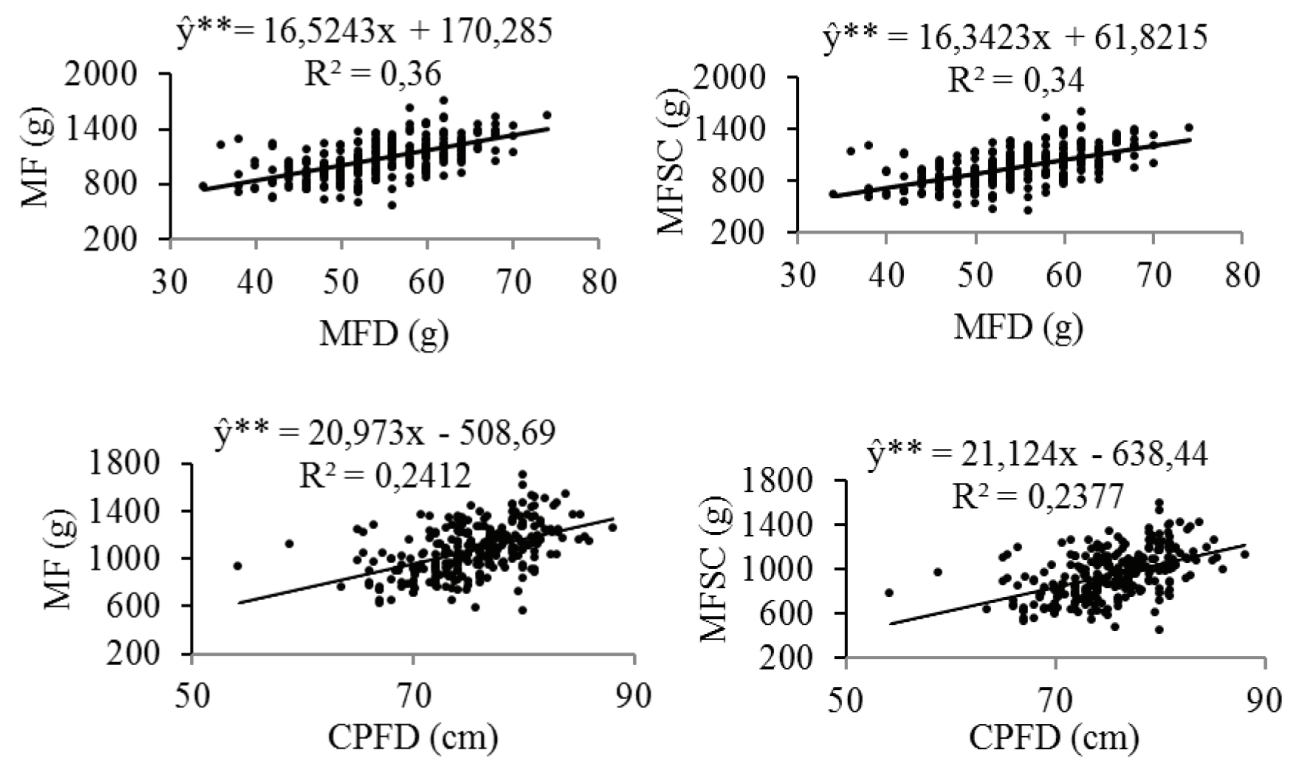

FIGURA 2- Regressão linear entre a massa e o comprimento da folha ' $\mathrm{D}$ ' (COMPFD) com a massa do fruto com (MFD) e sem (MFSC) coroa do abacaxizeiro 'BRS Imperial'.

** significativo a $1 \%$ de probabilidade, pelo teste $\mathrm{F}$.

\section{CONCLUSÃO}

A adubação potássica influenciou de forma positiva na massa, no comprimento da planta e no número de mudas por planta, enquanto a nitrogenada influenciou na emissão de folhas e na massa de mudas do abacaxizeiro 'BRS Imperial'.

$\mathrm{O}$ adubo nitrogenado reduziu o percentual de florescimento induzido artificialmente, enquanto o potássico aumentou o florescimento.

A massa máxima estimada da folha ' $\mathrm{D}$ ' foi de 56 g na dose máxima de $364 \mathrm{~kg} \mathrm{ha}^{-1}$ de $\mathrm{N}$ e na maior dose de adubo potássico (600 $\left.\mathrm{kg} \mathrm{ha}^{-1} \mathrm{de}_{2} \mathrm{O}\right)$.

\section{REFERÊNCIAS}

CABRAL, J.R.S.; MATOS, A.P. de 'Imperial', a new pineapple cultivar resistant to fusariosis. Acta Horticulturae, The Hague, n.822, p.47-50, 2009.

FARIA, D.C. de. Desenvolvimento e produtividade do abacaxizeiro 'Smooth Cayenne' em função de adubação nitrogenada e tipos de mudas no norte fluminense. 2008. $67 \mathrm{f}$. Tese (Mestrado) - Universidade Estadual do Norte Fluminense Darcy Ribeiro, Centro de Ciências e Tecnologias Agropecuárias, Campos dos Goytacazes, 2008.
GIACOMELLI, E.J. Expansão da abacaxicultura no Brasil. Campinas: Fundação Cargill, 1982. p.27-44.

GUARÇONI M., A.; VENTURA, J.A. Adubação N-P-K e o desenvolvimento, produtividade e qualidade dos frutos do abacaxi 'Gold' (MD-2). Revista Brasileira de Ciência do Solo, Viçosa, MG,v.35, n.4, p.1367-1376, 2011.

HEPTON, A. Cultural System. In: BARTHOLOMEW, D.P.; PAULL, R.E.; ROHRBACH, K.G. (Ed.). The pineapple: botany, production and uses. New York: University of Hawaii at Manoa, Cabi Publishing, 2003. p.109-142.

HORTIESCOLHA. Padrão mínimo de qualidade e equivalência de tamanho: abacaxi. Biblioteca Hortiescolha. 2015. Disponível em: http://www. hortiescolha.com.br/biblioteca/padrao-minimo-dequalidade-e-equivalencia-de-taman/. Acesso em: 16 jun. 2015.

KIST, H.G.K; RAMOS, J.D.; SANTOS, V.A. dos. Fenologia e escalonamento da produção do abacaxizeiro 'Smooth Cayenne' no Cerrado de Mato Grosso. Pesquisa Agropecuária Brasileira, Brasília, v.46, n.9, p.992-997, 2011. 
MALAVOLTA, E. Manual de nutrição de plantas. São Paulo: Editora Agronômica Ceres, 2006. 638p.

MALÉZIEUX, E.; CÔTE, F.; BARTHOLOMEW, D.P. crop environment, plant growth and physiology. In: BARTHOLOMEW, D.P.; PAULL, R.E.; ROHRBACH, K.G. (Ed.). The pineapple: botany, production and uses. New York: CABI Publishing, 2003. p.69-107.

OLIVEIRA, A.M.G.; CARDOSO, C.E.L.; JUNGHANS, D.T.; REINHARDT, D.H.; CUNHA, G.A.P. da; OLIVEIRA, J.L.; CABRAL, J.R.S.; SOUZA, L.F. da S.; SANCHES, N.F. Sistema de produção de abacaxi para o extremo sul da Bahia. Cruz das Almas: Embrapa Mandioca e Fruticultura, 2009. 63p. (Sistemas de Produção, 2)

PINHEIRO NETO, L.G. Crescimento, produção e qualidade do abacaxizeiro fertirrigado com diferentes fontes e doses de nitrogênio e potássio. 2009. $131 \mathrm{f}$. Tese (Doutorado) -Mossoró: Universidade Federal Rural do Semi-Árido, 2009.

RAMOS, M.J.; MONNERAT, P.H.; PINHO, L.G.R. da R.P. Leitura SPAD em Abacaxizeiro 'Imperial' Cultivado em Deficiência de Macronutrientes e de Boro. Revista Brasileira de Fruticultura, Jaboticabal, v.35, n. 1, p. 277-281, 2013.

RAMOS, M.J.M. Caracterização de sintomas de deficiência de macronutrientes e de boro em abacaxizeiro cultivar 'Imperial'. 2006. 95 f. Tese (Doutorado) - Campo dos Goytacazes, Universidade Estadual do Norte Fluminense Darcy Ribeiro, 2006. $95 \mathrm{p}$.

RAZZAQUE, A. H. M.; HANAFI, M. M. Effect of potassium on growth, yield and quality of pineapple in tropical peat. Fruits, Paris, v.56, n.1, p.45-49, 2001.
SAMPAIO, A.C.; FUMIS, T. de F.; LEONEL, S. Crescimento vegetativo e características dos frutos de cinco cultivares de abacaxi na região de BauruSP. Revista Brasileira de Fruticultura, Jaboticabal, v.33, n.3, p.816-822, 2011.

SANTOS FILHO, S. dos A.; LEAL, D. R. M.; PISSINATO, A. G. V.; JUNGHANS, D.

T. Correlação entre características de folha "D" e do fruto do abacaxi na cultivar BRS Imperial. In: REUNIÃO ANUAL DE CIÊNCIA, TECNOLOGIA, INOVAÇÃO E CULTURA NO RECÔNCAVO DA BAHIA - RECITEC RECÔNCAVO, 1., 2011, Cruz das Almas. Anais... Cruz das Almas: Universidade Federal do Recôncavo da Bahia, 2011. 1 CD-ROM.

SILVA, A.L.P.; SILVA, A.P.; SOUZA, A.P.; SANTOS, D.; SILVA, S.M.; SILVA, V.B. Resposta do abacaxizeiro 'Vitória' a doses de nitrogênio em solos de tabuleiros costeiros da Paraíba. Revista Brasileira de Ciência do Solo, Viçosa, v.36, n.2, p.447-456, 2012.

TEIXEIRA， L.A.J.; QUAGGIO, J.A.; CANTARELlA, H.; MELLIS, E.V. Potassium fertilization for pineapple: effects on soil chemical properties and plant nutrition. Revista Brasileira de Fruticultura, Jaboticabal, v.33, n.2, p.627-636, 2011.

UFV - Universidade Federal de Viçosa. SAEG Sistema de análises estatísticas e genéticas. Versão 7.1. Viçosa: Universidade Federal de Viçosa, 1997. $150 \mathrm{p}$.

VAN DE POEL, B.V.; CEUSTERS, J.; DE PROFT, M.P. Determination of pineaple (Ananas comosus, MD-2 hybrid cultivar) plant maturity, the efficiency of flowering induction agents and the use of activated carbon. Scientia Horticulturae, Wageningen, v.120, p.58-63, 2009. 